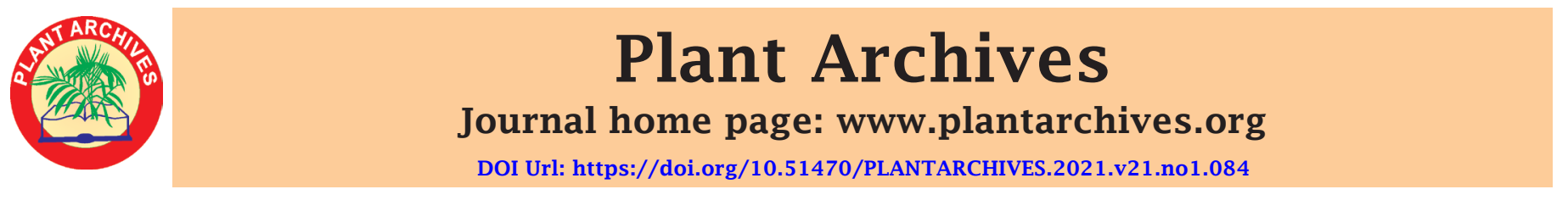

\title{
CONSEQUENCES OF EXPOSURE TO PHTHALATES, MICRO PLASTICS AND NANO-PLASTICS ON THE ORGANISMS
}

Simran and Mahendra P. Singh*

School of Bioengineering and Biosciences, Lovely Professional University, Delhi-Jalandhar GT Road, Phagwara-144411

(Punjab), INDIA

*Email: mahendra.19817@lpu.co.in

(Date of Receiving-11-11-2020; Date of Acceptance-09-02-2021)

\begin{abstract}
Study of Microplastice, Polystyrene and phthalates (BPA, DBP, and DEHP) is as popular as scientists use them as a key point to reach up the new approaches. Toxicity of Phthalates and plastic components come through various sources that we are using in our daily life and it results in hazardous impacts on vertebrates and non-vertebrates organisms. Previous researches on the effect of these components have been done by using the model organisms. This review paper contains the information of past studies regarding toxicity of Microplastic and phthalates in vertebrates like mammals (human beings and whale), aquatic organisms, Zebra fish (Danio rerio) and invertebrates including D. melanogaster, D. pulex and D. magna. Ingestion of phthalates and plastic components in organisms takes place due to the contaminated water and food. Many research papers

ABSTRACT studies have explained that, those 44 organisms (weather aquatic or terrestrial) who consume plastic and phthalates through their contaminated food with different concentrations always suffer from some morphological, behavioral, biochemical and reproductive deformities. Ingestion of these components into the organisms contains a proper cycle of food web. Each and every organism hasa direct or indirect impact of Micro plastic and phthalates. Some scientists also explained that how a pregnant woman can be responsible for the disease in fetus and infants after consumption of these compounds. Male and female have different types of toxicity in their body functions including hormonal disturbance. So, plastic and phthalates have adverse consequences on aquatic life and human health
\end{abstract}

Keywords: Microplastic, phthalates, nano sized plastic, invertebrate organisms and vertebrate organisms.

\section{INTRODUCTION}

Most advanced culture of humans over the previous century has been encouraged by the utilization of plastics. Plastics are made out of an organization of atomic monomers bound together to frame macromolecules of limitless use to human culture. Plastics are flexible, practical, require less energy to create than elective materials like metal or glass, and can be made to have various properties (North et al., 2013). The measure of bungled plastic waste produced yearly by populaces living inside $50 \mathrm{~km}$ of a coast worldwide that can possibly enter the sea as marine garbage. Plastics in the marine climate are of expanding concern in light of their diligence what's more, impacts on the seas, untamed life, and, conceivably, people. Plastic flotsam and jetsam happen on coastlines, in Arctic Ocean ice, at the ocean surface, and on the ocean bottom (Jambeck et al., 2015). Plastic contamination is found in earthbound and marine conditions and is corrupted to miniature particles (MP) what's more, nano-particles (NP) of plastic. The clearest plastic contamination emerges from enormous (full scale) things, counting bottles, containers, food wrappings, plastic straws and restorative items. The sizes of Microplastics are microscopic: 50 micrometer $5 \mathrm{~mm}(0.05-5 \mathrm{~mm})$, Nanoplastics are smaller than algal cell i.e. 1,000 times, $(1.0 \mu \mathrm{m}-100 \mathrm{~nm})$. Nanoplastics are particles that consolidate different polymers (for example PET - Polyethylene terephthalate, PS-Polystyrene).
Subordinate upon the definition utilized they are under 1 micrometer or under $100 \mathrm{~nm}$ in size, autonomously. Subsequently, the term nanoplastic doesn't outline a uniform material. It is essential to see central and right hand nanoplastics (Waring et al., 2018).

\section{Micro And Nano Plastic}

The amount of microplastics in the climate is probably going to increment because of the tradition of plastic things which defile the planet. Given the proof recommending human introduction to microplastics and their related toxins is conceivable, it is critical to survey the danger they posture to human wellbeing (Wright et al., 2017). Plastic has gained a critical status, with wide business, current, helpful and common applications. Solicitation is broad; yearly plastic creation has extended essentially from 1.5 million tons during the 1950 s to around 280 million tons in 2011 (Wright et al., 2013). A couple of assessments have investigated the introduction of invertebrate and vertebrate species to nanoplastics, recollecting their responses for terms of bioaccumulation, malignancy counteraction operator, heat stagger proteins, and age (Liu et al., 2018). Plastic trash gathers in the earth and its crumbling into humbler particles raised amazing worries starting late on their conceivable impact on environmental prosperity. Particles in nanoscale were known to be more harmful than unwieldy materials, yet past destructiveness 
appraisal on nanoplastic particles (NPP) just occasionally considered the effect of biological components, which in no little degree direct the lead and study of these particles (Fadare et al., 2019). Creating nanotechnology has advanced another arrangement of materials and openings for various mechanical and shopper items. Nano materials (NMs) are described by their measurements in the scope of 1-100 nm (Schirinzi et al., 2017). Accordingly, worries about dangers to marine natural life upon introduction to the fluctuated types of plastic garbage have expanded, invigorating new examination into the degree and results of plastics tainting in the marine condition, the proceeded quick development in plastics creation, and the proofthough restricted — of shown effects on marine natural life uphold prompt execution of source-diminishing measures to diminish the likely dangers of plastics in the marine environment (Law 2017).

TABLE 1: - Deposition of plastic garbage in oceans (review in advance 2016).

\begin{tabular}{|l|c|}
\hline NAME OF CHEMICALS & $\begin{array}{c}\text { DEPOSITION } \\
\text { PERCENTAGE }\end{array}$ \\
\hline Polyethylene & $29 \%$ \\
\hline Polypropylene & $17 \%$ \\
\hline Polyvinyl Chloride & $9 \%$ \\
\hline Polyurethane & $7 \%$ \\
\hline Polyethylene Terephthalate & $8 \%$ \\
\hline Polycarbonate & $14 \%$ \\
\hline Polystyrene & $6 \%$ \\
\hline Other & $4 \%$ \\
\hline Additives & $6 \%$ \\
\hline
\end{tabular}

\section{Phthalates}

This introduction is of extraordinary worry, as phthalates have been suspected to have against androgenic and estrogenic impacts, which may modify the conceptive improvement of kids. To be sure, toxicological proof proposes that some phthalates, including butyl benzyl phthalate (BBzP), di-n-butyl phthalate (DnBP), and di(2-ethylhexyl) phthalate (DEHP), may adjust or emulate estradiol (E2) in vivo and in vitro. Creature contemplates demonstrate that gestational phthalate introduction is related with antagonistic wellbeing results, including disturbance of endocrine and conceptive capacity and advancement. Besides, it was proposed that most regenerative impacts of phthalates are not applied by phthalates fundamentally, but instead their metabolites (Hua Su et al., 2014). Phthalates which are low atomic weight (LMW) are generally changed over to their monoesters and excreted. The 10 phthalates most regularly utilized in purchaser items are dimethyl phthalate (DMP), diethyl phthalate (DEP), dibutyl phthalate (DBP), diisobutyl phthalate (DiBP), benzylbutyl phthalate (BzBP), phthalate (DCHP), DEHP, di-n-octyl phthalate (DnOP), diisononyl phthalate (DiNP), and di-isodecyl phthalate (DiDP) (Dutta et al., 2020).

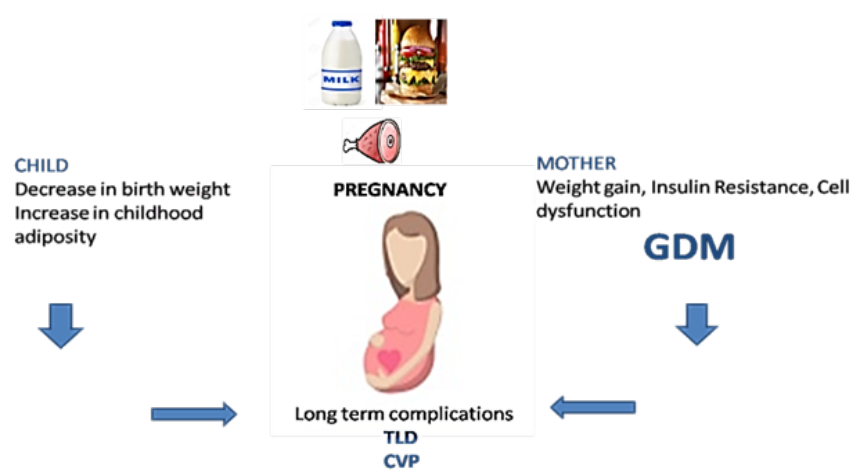

Fig1: Consequences of Phthalates among pregnant women (Filardi et al., 2020)

Pregnant ladies are presented to an assortment of synthetic compounds, counting endocrine-upsetting synthetic Substances (EDCs, for example, phthalates and bisphenols. Expanding proof recommends that early life presentations to phthalates and bisphenols may add to the weight of cardiovascular and metabolic malady in western nations. Late work recommends that these presentations might be expensive. Medical services expenses of stoutness and diabetes owing to grown-up phthalate and bisphenol introduction in Europe are in the request for D 17 billion yearly. To the extent that pre-birth and youth presentations may even be more effective, the expense cardiometabolic conditions because of these introductions might be huge (Philips et al., 2016).

TABLE 2:- Full names and abbreviations of phthalates and their metabolites (Hollerer 2018)

\begin{tabular}{|l|c|c|c|}
\hline PHTHALATE NAME & ABBREVIATIONS & URINARY METABOLITES & ABBREVIATIONS \\
\hline Dimethyl Phthalate & DMP & Mono-n-methyl Phthalate & MnMP \\
\hline Diethyl Phthalate & DEP & Mono-ethyl Phthalate & MEP \\
\hline Di- isobutyl Phthalate & DiBP & Mono-isobutyl Phthalate & MiBP \\
\hline Di-n-butyl Phthalate & DnBP & Mono-n-butyl Phthalate & MnPP \\
\hline Di-n-octyl Phthalate & DnOP & Mono-(3-carboxypropyl) Phthalate & MCPP \\
\hline Di-isononyl Phthalate & DiNP & Mono-carboxyoctyl Phthalate & MCOP \\
\hline Di-isodecyl Phthalate & DiDP & Mono-carboxynonyl Phthalate & MBNP \\
\hline Benzylbutyl Phthalate & BzBP & Mono-benzyl Phthalate & MEHP \\
\hline Di-2-ethylhexyl Phthalate & DEHP & Mono-2-ethylhexyl Phthalate & \\
\hline
\end{tabular}




\section{Toxic and destructive impact of phthalates on Drosophila melanogaster}

Drosophila is the organism which has strong resistance power against the infection, but still many things affect them. Micro sized, nanosized plastic and Phthalates also have some effect on them. According to the previous studies we got that, the humoral immune system by injecting polystyrene beads into hemocytes, they stop entry and not allow moving bacteria inside; it means they help in fighting against the infection and made Drosophila resistant from viruses and bacteria (Erickson et al., 2000). Wild types fly mostly die, they cannot stop entry of bacteria (Erickson et al., 2000). Drosophila introduced to DEHP show extended starvation impediment, cut down surrounding starch levels and extended accumulated lipid, similarly as changes of metabolic-related quality transcripts. DEHP dealing with possibly upsets sugar homeostasis and starts a diabeteslike metabolic brokenness (Coa et al., 2016). DBP effects insulin and make disturbance in male flies, by managing quality includes in lipid, glucose and xenobiotic digestion (Williams et al., 2016). DBP influence formative time and cause diminishes in the quantity of posterity in $D$. melanogaster (Atli, Emel, 2010). BPA causes an expansion in monotonous conduct in Drosophila melanogaster. The pre-birth BPA presentation causes an expansion in redundant or generalized developments, with seriousness expanding with expanding BPA presentation fixation. BPA cause neurodevelopment disorder in Drosophila like autism and seeking nature. There is change in behavior also that increase in peristaltic contraction (Streifel, 2016). DBP is processed to monobutyl phthalate (MBP) in uncovered Drosophila males and that MBP is more lethal than DBP, as saw in higher creatures (Misra et al., 2014). LUSH is a dissolvable odorant-restricting protein of the natural product fly Drosophila melanogaster. LUSH ties some phthalates and that flies are repulsed by such mixes. Drosophila melanogaster have different combinations of ethanol similarly as to dibutyl phthalate, which wind up being the best ligand of LUSH (Zhou et al., 2004). Meanwhile, DEHP also diminished the repeat and sufficiency of mEPSCs. Additionally, molecule channel thinks about showed DEHP frustrated the top current ampleness of calcium channel. These results showed that the DEHP adjusted the cholinergic minimal synaptic transmission of projection neurons in Drosophila antennal fold, and this change might be intervened by controlling the calcium channel works out (Ran et al., 2012). D. melanogaster reacted to raising oxygen level with compensatory morphological changes in the little tracheae and tracheoles, anyway held sufficiency in an enormous bit of the other essential sections of the tracheal stock to the flight muscles (Harrison et al., 2017). Three standard plasticizers (one trimellitate and two phthalates) were thought close by the ILs (ionic liquids), with DEHP picked explicitly as a result of its all-inclusive use. cytotoxic effects of, ILs being more destructive than the standard plasticizer DEHP on D. melanogaster S2 Cell the way that no solicitation for enormity differentiate in cell thickness was viewed (Rahman et al., 2010). After coming in contact with xenobiotic chemicals like (DEHP, DBP and BADGE) drosophila become highly resistant to starvation and diminished degrees of coursing just as expended lipid content. There is also high oxidative resistant (Larsson, 2018). Impact of natural compound BPA on genome-wide quality articulation of Drosophila can be improved by the ingestion of sugar (Branco, Lemos, 2014). DEHP and MEHP were negative when measured for the enlistment of sex-connected passive lethal in Drosophila melanogaster (Melnick et al., 1987). DEHP additionally didn't show genotoxicity in Drosophila. When hatchlings were all the while treated with DEHP and N-nitrosodimethylamine (NDMA), the DNA harming movement of NDMA was expanded in the Drosophila DNA fix test. Besides, DNA twofold strand breaks were expanded by a similar treatment of Drosophila. So, DNA twofold strand breaks cause the cogenotoxic impact of DEHP in Drosophila (Kawai, 1998). A new cultivation system called bottle system also proved that DEHP decreases the life line of D. melanogaster (Li et al., 2010). The level of phagocytosis of PS (Polystyrene) dabs after implantation of globules of different sizes into Drosophila hatchlings, a sensible decline in the limit of resistant cells to phagocyte, which is close to the protected cell broadness. The phagocytic power can be determined by the phagocytized dabs surface (Adolfsson et al., 2018).

\section{Assessment of Phthalates and plastic on Vertebrates}

Microplastic plenitudes have been thought little of all around the world. This little size range is significant in light of the fact that it sits inside the taking care of scope of numerous zooplankton, demonstrating the expected introduction, and danger of tropic move might be higher than recently thought of (Hitchcock et al., 2019).

\section{Mammals}

Oxidative pressure is one of the instruments of cytotoxicity at cell level, as has been watched for both cell lines and add to the current information on the impacts of NMs and MPLs-NPLs (Schirinzi et al., 2017). Inward breath or ingestion of microplastics may cause tissue irritation. Besides, the arrival of risky synthetic and microorganisms from the MP surface may expand the danger (Chen et al., 2019). Just microplastics littler than $20 \mathrm{~mm}$ ought to have the option to enter organs, and those with a size of around $10 \mathrm{~mm}$ ought to have the option to get to all organs, cross cell layers, cross the blood-mind obstruction, and enter the placenta, accepting that a conveyance of particles in optional tissues, for example, the liver, muscles, and the mind is conceivable to human wellbeing (Campanale et al., 2020). MPs could additionally fill in as a vector for microorganisms, prompting possibly scattering of species in another environment (Revel et al., 2018). The expanding rate of neurodegenerative illnesses, invulnerable problems and tumors may likewise be identified with the expanded introduction to ecological pollutants, including microplastics. Microplastics may cause provocative injuries, beginning from the capability of their surface to 
collaborate with the tissues (Prata et al., 2019). There is expanded apoptosis; expanded responsive oxygen species (ROS) age furthermore, expanded sperm aneuploidy with expanding DEHP introduction, which may help educate potential systems of activity. Generally speaking, there is moderate proof of a relationship between expanded DEHP and diminished semen quality, especially for sperm focus (Radke et al., 2018).DEHP in the male regenerative framework, a few creators related that higher phthalate monoester focuses were related with decreased testosterone levels, higher SHBG levels and LH/free testosterone proportion. These changes are related with diminished movement of androgens, what's more, may influence leydig cell work. In rodents, it was shown that DEHP prompts fetal hindrance of testosterone creation (Mariana et al., 2016). DEHP use has been confined due to the potential unfavorable impacts, and DEHP presentation levels in individuals at higher danger have subsequently absolutely been diminished (Lto et al., 2019). As ocean nourishments people are ingesting miniature and Nanosized estimated plastic. Subsequent to collecting, shellfish are typically kept in clean water to dispose of pollutants. The shellfish remove some microplastics, while others remain inside, arrive at the market and end up on the customer's plate (Smith et al., 2018). It has been induced that phthalates could go about as a tracer for Microplastic ingestion by Mediterranean blade whales (Balaenoptera physalus) in light of the fact that high convergences of these plasticizers were distinguished in territories that compared with the spatial dissemination of the whales. The large occurrence of particles is fibers (84\%) while the staying $16 \%$ was sections. Particles were basically blue and dark (42.5\% and $26.4 \%)$ in shading and Nylon was the most common (60\%) polymer type (Nelmsw et al., 2018). Movement of moderately enormous (particles can happen over the vertebrate gut by means of per sorption (the section of particles through the epithelial layers of the gastro-intestinal lot), while littler particles are taken up through typical stomach related cycles (Parton et al., 2020). Ingested Micro and Nano plastic would initially experience the intestinal epithelium and aggravation of the gut lining. Collection of Micro and Nano plastic in liver tissues and constant irritation could prompt liver illnesses also, metabolic issues (Yong et al., 2020). PVC and material divider materials in homes were connected to improvement of bronchial block in Norwegian kids (Kwan et al., 2020). Phthalates have a lower intensity of estrogenic action as contrasted and endogenous steroid estrogens and are available in low levels in human tissues (Chen et al., 2018).

DEHP actuate the development of stomatocytes in red platelets (RBCs) at focuses as low as ng/ $\mathrm{mL}$. Different phthalates (counting DBP) have harmfulness against the WI-38 cell line, which is gotten from fibroblasts from the tissue of lungs in human beings. The presence of DBP, BBP and DEHP phthalates influences the in vitro development

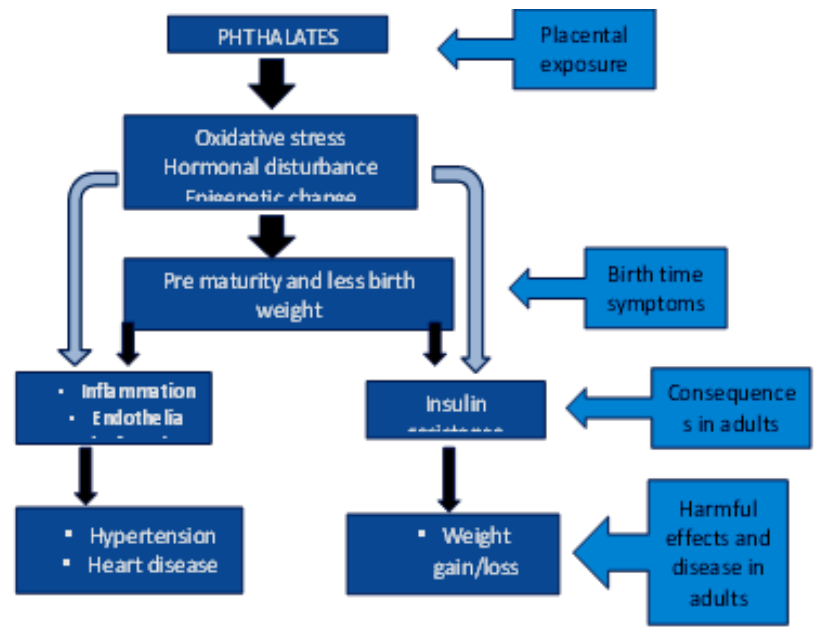

Fig 2: Effect of phthalates from new born to adulthood (Philips et al., 2016)

of human hematopoietic foundational microorganisms segregated from the umbilical rope blood, the DBP is the most toxic of the phthalates tried (Garacia et al., 2019). Focuses of $\mathrm{mEP}$ were higher in pregnant ladies who utilized filtered water for cooking $48 \mathrm{~h}$ before introduction appraisal than in ladies who utilized the tap water gracefully. Dietary segments or examples are significant wellsprings of BPA, high MWPs, also, low MWPs in pregnant women (Pacyga et al., 2019). Higher pre-birth presentation to explicit phthalates was related with lower engine work among 11-year old young ladies while higher postnatal introduction to DEHP metabolites was related with lower scores among young men. As lower scores on proportions of engine improvement have been related with more issues in intellectual, motional feelings working and conduct, the discoveries have suggestions identified with in general kid advancement (Balalian et al., 2019).

Taiwan's pork and chicken are satisfactory in quality and are adequately protected. Phthalate introduction among grown-ups in Taiwan seems to represent an insignificant danger to human wellbeing. It is suggested that future examines utilize hazard evaluations of meat utilization for Taiwanese kids (Tsai et al., 2019).

\section{Aquatic vertebrates}

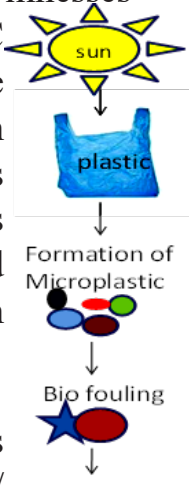
Contamination

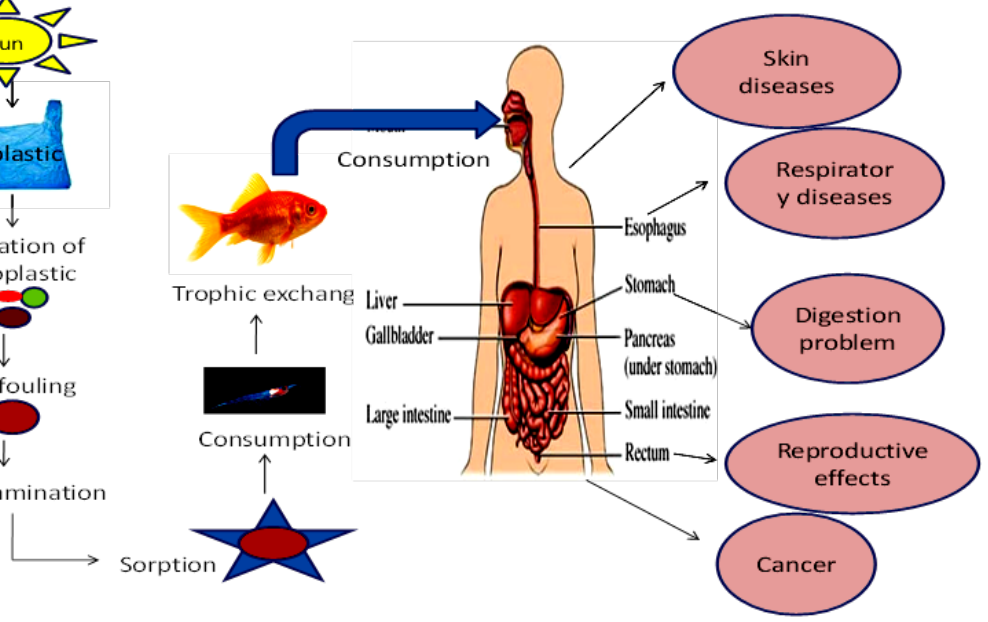

Fig 3: Ingestion and effect of plastic in human beings 
Microplastics pollution could happen in nearly a wide range of oceanic environments around the world. Microplastics ingestion by fish generally originates from the examination of gastrointestinal lots in fish (Wang et al., 2019). Fish that depend basically on visual scrounging prompts ingested Microplastic particles significantly more often and in higher numbers than species that perform essentially chemosensory rummaging, recommending that a feeling of taste helps separation of unpalatable food things (Roch et al., 2020). Polystyrene (PS), impervious to biodegradation can gather in the stomach of fish and can move through blood flow. Microplastics can move bacterial gatherings in freshwater environments (Li et al., 2017). Microplastics can join or get truly ingested by practically all amphibian taxa or influence biota through leachates or microorganisms from the Microplastic surface. Microplastics can be a vector of microbes into the tissue of creatures. Microplastic is bio available to the littlest of life forms, auxiliary ingestion can happen, which might be directed through the food web (Prinz and Korez 2020).

\section{Zebra fish (Danio rerio)}

Microplastic was seen in the zebra fish gut, which caused aggravation and oxidative worry in the gut tissues. The gut metabolic problems, including the amino corrosive digestion what's more, lipid digestion, were seen in the MPs-treated zebra fish. $78 \%$ and $86 \%$ of the intestinal harm in Zebra fish with presentation to microplastics (Qiao et al., 2019). Microplastics were first ingested, got amassed, and thus caused rotations in motion, intestinal harm and moreover, change in metabolic profiles (Li et al., 2017). 500-600 $\mu \mathrm{m}$ particles gathered in the gills and digestive tract of grown-up zebra fish, while 10-22 $\mu \mathrm{m}$ particles gathered distinctly in the digestive tract. The consequences for the aryl hydrocarbon receptor pathway, disturbance of the oogenesis cycle, and neurotoxicity could be brought about by intense introduction of grown-up zebra fish to microplastics (Mak et al., 2019). Shape-subordinate collection of microplastics in the gut of zebra fish was watched more in strands and lesser in globules. Microplastic strands brought about additional extreme intestinal poisonousness than micro plastic sections and globules did. Mucosal harm, expanded penetrability, aggravation, digestion disturbance and microbiota dysbiosis was mostly found in the gut (Qiao et al., 2019). More modest particles $(5 \mathrm{~mm})$ can all the more effectively be collected in zebrafish gills, liver, and gut following seven days of introduction than bigger estimated $20 \mu \mathrm{m}$ distance across microplastics. Furthermore, it was discovered that microplastics with a more modest size $(5 \mathrm{~mm})$ principally collected in interior tissues (liver and gut) instead of in outside tissues (gills). Exposure to microplastics fundamentally diminished swimming capability in zebrafish hatchlings in the free swimming test, yet in addition in the light-to-dull variation incitement in dim period and increment the safeguard reaction at the atomic level in treated zebrafish hatchlings, which may add to the diminished swimming execution (Qiang et al., 2019).There is different and broad change in the quality articulation of Zebra fish hatchlings after 48-h of presentation to Microplastic. Hatchlings presented to MPs, basically the ones in bunches 50 and $100 \mathrm{mg} / \mathrm{L}$, introduced more critical outer phonotypical changes and higher drastic variation from the norm rates, and this observation proposes the sublethal effect of MPs (Malafaia et al., 2019). Collection of Microplastic in the circulatory framework might be brought about by mouth-gastrointestinal lot movement and legitimately from fringe vessels through gill/transdermal ingestion. More modest nano plastics can enter these pores in the incipient organism stage though particles bigger than pore size can stick to the chorion and brought inside by water stream or mixed up as food by hatchlings (Bhagat et al., 2020). Presence of microplastics in zebra fish dung inferred that round microplastics may encourage egestion from the body comparative with divided microplastics. Microplastic pieces have sharp edges, which improve the probability of physical micro injuries and maintenance in the gastrointestinal divider and gill fibers (Mak et al., 2019).

\section{Assessment of plastic on Invertebrates}

The effects of marine trash on biodiversity uncovered that around $80 \%$ of revealed episodes among life forms and marine garbage was related with plastic while $11 \%$ of all detailed experiences are with microplastics. Poisonousness could likewise emerge from draining constituent foreign substances for example, monomers and plastic added substances, fit for causing carcinogenesis and endocrine disturbance. Microplastics may not just enter the evolved way of life by means of ingestion, as they have exhibited an ability to adsorb to living animals (Wright et al., 2013).

\section{Daphnia}

Daphnia are plank tonic scavengers that have a place with the Phyllopoda (some of the time called Branchiopoda), which are described by straightened leaf-like legs used to create a water momentum for the separating mechanical assembly. The assemblage of Daphnia is generally 1-5 millimeters (0.04-0.20 in) long (Ebert, 2005). For $D$. pulex presented to nanoplastic, relative articulation of HSP70 arrived at its most significant levels in 21-dayold creatures. D.pulex influences the affectability of its people to contamination from this nanoplastic, essentially through changes to fundamental physiological and biochemical cycles, such as cell energy homeostasis and oxidation, which were exhibited in vivo (Liu et al., 2018). In Daphnia pulex nanoplastic caused the excess production of ROS alongside other portion subordinate impacts. Low nanoplastic focuses $(0.1$ as well as $0.5 \mathrm{mg} / \mathrm{L})$ altogether expanded the declarations of qualities of the MAPK pathway (Liu et al., 2020). Total expands the molecule size consequently decreasing the absolute surface region, while precipitation of NPP would conceivably diminish the introduction danger of D. magna to NPP (Wan et al., 2019). Neither expanded mortality nor changes in body shape or regenerative boundaries were watched for grown-up Daphnia. Both morphology and ancestral life of D. magna 607 
indicated an assortment of noteworthy yet little contrasts in body length, body width and tail spine length (Imhof et al., 2017).

\section{CONCLUSION}

Overall, there is no positive impact of plastic on environment. If we see around us then small to small thing is containing plastic and Phthalates either in direct way or indirect. Plants, animals and humans get toxicity in their body function because of plastic. In this review we found that plastic consumption in human being and other organisms in the form of Microplastic and nano plastic after fragmentation of Plastic, from aquatic to terrestrial organism it get ingested with the food and drinking elements. If we talk about humans, then ingestion of Microplastic can cause hazardous disease like cancer, neurological problems, reproductive problems, developmental, toxicity and impairment of immune system. Aquatic animals cause deformities because of human activities like from industrial waste, domestic garbage which is thrown in the water bodies. Those creatures engulf them by imagining it as a food and then suffer with so many diseases. Most major effect of plastic is on aquatic ecosystem. Most of the microplastics are found in the gut region of fishes. Some of the aquatic organisms lead to the death even because of blockage in gills with Microplastic. Phthalates have major effects on the human beings and ratio of effect in male is more than females. Phthalates can cause fluctuation in sex hormones levels, deformities in genitals development, low sperm count in males. Even the infants and fetus also get impact of phthalates. Children also facing problems in their life style due to consumption of phthalates like obesity, Hypertension etc. Women are facing some serious impact of it like decrease rate in fertility, more chances of miscarriage and breast cancer, Pregnant ladies if get in contact with Phthalates then they have to suffer with long time complications. Model organism Drosophila melanogaster have change in its morphology, behavior and genetic variations after treating with phthalates. $D$. melanogaster and humans have same effects of phthalates up to some extents because it is a model organism and have $60 \%$ gene homology. A very small organism which is considered as Non-vertebrate called Daphinahas major effect of nano sized plastic on morphology and body functioning and out of two species in Daphnia, D. pulex have great threat of plastic then D. magna. Albeit a few distributed investigates have definite significant issues on the subject of microplastics and the important natural and wellbeing sway, there are a couple of papers to investigate the improvement of guidelines and the executives approaches to control boundless microplastics in nature.

\section{REFERENCES}

Adolfsson, K., Abariute, L., Dabkowska, A. P., Schneider, M., Häcker, U., \&Prinz, C. N. (2018). Direct comparison between in vivo and in vitro microsized particle phagocytosis assays in Drosophila melanogaster. Toxicology in Vitro, 46, 213-218.
Alshawafi, A., Analla, M., Alwashali, E., Ahechti, M., \&Aksissou, M. (2018). Impacts of marine waste, ingestion of microplastic in the fish, impact on fishing yield, M'diq, Morocco. International journal of marine biology and research, 47, 60 .

Amato-Lourenço, L. F., dos Santos Galvão, L., de Weger, L. A., Hiemstra, P. S., Vijver, M. G., \&Mauad, T. (2020). An emerging class of air pollutants: Potential effects of microplastics to respiratory human health? Science of The Total Environment, 141676.

Atli, E. (2010). The effect of dibutyl phthalate (DBP) on the development and fecundity of Drosophila melanogaster. Drosophila Information Service, 93, 164.

Balalian, A. A., Whyatt, R. M., Liu, X., Insel, B. J., Rauh, V. A., Herbstman, J., \& Factor-Litvak, P. (2019). Prenatal and childhood exposure to phthalates and motor skills at age 11 years. Environmental research, 171, 416-427.

Bhagat, J., Zang, L., Nishimura, N., \& Shimada, Y. (2020). Zebrafish: An emerging model to study microplastic and nanoplastic toxicity. Science of the Total Environment, 138707.

Branco, A. T., \&Lemos, B. (2014). Interaction between bisphenol A and dietary sugar affects global gene transcription in Drosophila melanogaster. Genomics data, 2, 308-311.

Campanale, C., Massarelli, C., Savino, I., Locaputo, V., \&Uricchio, V. F. (2020). A detailed review study on potential effects of microplastics and additives of concern on human health. International Journal of Environmental Research and Public Health, 17(4), 1212.

Cao, H. (2018). Exposure to xenobiotic chemicals disrupts metabolism, rhythmicity and cell proliferation in Drosophila melanogaster (Doctoral dissertation, ActaUniversitatisUpsaliensis).

Cao, H., Wiemerslage, L., Marttila, P. S., Williams, M. J., \&Schiöth, H. B. (2016). Bis-(2-ethylhexyl) Phthalate Increases Insulin Expression and Lipid Levels in Drosophila melanogaster. Basic \& clinical pharmacology \& toxicology, 119(3), 309-316.

Carbery, M., O’Connor, W., \&Palanisami, T. (2018). Trophic transfer of microplastics and mixed contaminants in the marine food web and implications for human health. Environment international, 115, 400-409.

Chen, F. P., Chien, M. H., Chen, H. Y., \& Ng, Y. T. (2018). Effects of phthalates on normal human breast cells cocultured with different fibroblasts. PloS one, 13(6), e0199596.

Chen, G., Feng, Q., \& Wang, J. (2020). Mini-review of microplastics in the atmosphere and their risks to humans. Science of The Total Environment, 703, 135504.

Ebert, D. (2005). Introduction to Daphnia biology. Ecology, Epidemiology and Evolution of Parasitism in Daphnia, 
$5-18$.

Elrod-Erickson, M., Mishra, S., \& Schneider, D. (2000). Interactions between the cellular and humoral immune responses in Drosophila. Current Biology, 10(13), 781784.

Fadare, O. O., Wan, B., Guo, L. H., Xin, Y., Qin, W., \& Yang, Y. (2019). Humic acid alleviates the toxicity of polystyrene nanoplastic particles to Daphnia magna. Environmental Science: Nano, 6(5), 1466-1477.

Filardi, T., Panimolle, F., Lenzi, A., \&Morano, S. (2020). Bisphenol A and Phthalates in Diet: An Emerging Link with Pregnancy Complications. Nutrients, 12(2), 525.

Gutiérrez-García, A. K., Flores-Kelly, J. M., Ortiz-Rodríguez, T., Kalixto-Sánchez, M. A., \& De León-Rodríguez, A. (2019). Phthalates affect the in vitro expansion of human hematopoietic stem cell. Cytotechnology, 71(2), 553-561.

Harrison, J. F., Waters, J. S., Biddulph, T. A., Kovacevic, A., Klok, C. J., \&Socha, J. J. (2018). Developmental plasticity and stability in the tracheal networks supplying Drosophila flight muscle in response to rearing oxygen level. Journal of insect physiology, 106, 189-198.

Hitchcock, J. N., \&Mitrovic, S. M. (2019). Microplastic pollution in estuaries across a gradient of human impact. Environmental Pollution, 247, 457-466.

Imhof, H. K., Rusek, J., Thiel, M., Wolinska, J., \&Laforsch, C. (2017). Do microplastic particles affect Daphnia magna at the morphological, life history and molecular level? PloS one, 12(11), e0187590.

Ito, Y., Kamijima, M., \& Nakajima, T. (2019). Di (2-ethylhexyl) phthalate-induced toxicity and peroxisome proliferatoractivated receptor alpha: a review. Environmental health and preventive medicine, 24(1), 47.

Jambeck, J. R., Geyer, R., Wilcox, C., Siegler, T. R., Perryman, M., Andrady, A., ...\& Law, K. L. (2015). Plastic waste inputs from land into the ocean. Science, 347(6223), 768-771.

Kawai, K. (1998). Enhancement of the DNA damaging activity of N-nitroso dimethylamine by di-(2-ethylhexyl) phthalate in somatic cells in vivo of Drosophila melanogaster. Biological and Pharmaceutical Bulletin, 21(6), 579-582.

Kwan, W. S., Nikezic, D., Roy, V. A., \& Yu, K. N. (2020). Multiple Stressor Effects of Radon and Phthalates in Children: Background Information and Future Research. International Journal of Environmental Research and Public Health, 17(8), 2898.

Li, S., Chen, K., Li, X., Zhang, X., \& Liu, S. V. (2010). A new cultivation system for studying chemical effects on the lifespan of the fruit fly. Experimental gerontology, 45(2), 158-162.

Mak, C. W., Yeung, K. C. F., \& Chan, K. M. (2019). Acute toxic effects of polyethylene microplastic on adult zebrafish. Ecotoxicology and environmental safety, 182, 109442.

Malafaia, G., de Souza, A. M., Pereira, A. C., Gonçalves, S., da Costa Araújo, A. P., Ribeiro, R. X., \& Rocha, T. L. (2020). Developmental toxicity in zebrafish exposed to polyethylene microplastics under static and semi-static aquatic systems. Science of The Total Environment, 700, 134867.

Mariana, M., Feiteiro, J., Verde, I., \&Cairrao, E. (2016). The effects of phthalates in the cardiovascular and reproductive systems: a review. Environment international, 94, 758-776.

Melnick, R. L., Morrissey, R. E., \&Tomaszewski, K. E. (1987). Studies by the National Toxicology Program on di (2-ethylhexyl) phthalate. Toxicology and industrial health, 3(2), 99-118.

Misra, S., Singh, A., CH, R., Sharma, V., Reddy Mudiam, M. K., \& Ram, K. R. (2014). Identification of Drosophilabased endpoints for the assessment and understanding of xenobiotic-mediated male reproductive adversities. Toxicological Sciences, 141(1), 278-291.

Nelms, S. E., Barnett, J., Brownlow, A., Davison, N. J., Deaville, R., Galloway, T. S., ...\& Godley, B. J. (2019). Microplastics in marine mammals stranded around the British coast: ubiquitous but transitory? Scientific Reports, 9(1), 1-8.

North, E. J., \&Halden, R. U. (2013). Plastics and environmental health: the road ahead. Reviews on environmental health, 28(1), 1-8.

Pacyga, D. C., Sathyanarayana, S., \&Strakovsky, R. S. (2019). Dietary Predictors of Phthalate and Bisphenol Exposures in Pregnant Women. Advances in Nutrition, 10(5), 803815.

Parton, K. J., Godley, B. J., Santillo, D., Tausif, M., Omeyer, L. C., \& Galloway, T. S. (2020). Investigating the presence of microplastics in demersal sharks of the North-East Atlantic. Scientific reports, 10(1), 1-11.

Prata, J. C., da Costa, J. P., Lopes, I., Duarte, A. C., \& Rocha-Santos, T. (2020). Environmental exposure to microplastics: An overview on possible human health effects. Science of the Total Environment, 702, 134455.

Qiang, L., \& Cheng, J. (2019). Exposure to microplastics decreases swimming competence in larval zebrafish (Daniorerio). Ecotoxicology and environmental safety, 176, 226-233.

Qiao, R., Deng, Y., Zhang, S., Wolosker, M. B., Zhu, Q., Ren, H., \& Zhang, Y. (2019). Accumulation of different shapes of microplastics initiates intestinal injury and gut microbiota dysbiosis in the gut of zebrafish. Chemosphere, 236, 124334.

Qiao, R., Sheng, C., Lu, Y., Zhang, Y., Ren, H., \&Lemos, B. (2019). Microplastics induce intestinal inflammation, oxidative stress, and disorders of metabolome 
and microbiome in zebrafish. Science of the Total Environment, 662, 246-253.

Quesada-Calderón, S., Bacigalupe, L. D., Toro-Vélez, A. F., Madera-Parra, C. A., Peña-Varón, M. R., \& CárdenasHenao, H. (2017). The multigenerational effects of water contamination and endocrine disrupting chemicals on the fitness of Drosophila melanogaster. Ecology and evolution, 7(16), 6519-6526.

Radke, E. G., Braun, J. M., Meeker, J. D., \& Cooper, G. S. (2018). Phthalate exposure and male reproductive outcomes: a systematic review of the human epidemiological evidence. Environment international, 121, 764-793.

Rahman, M., O’Donnell, J. M., \&Brazel, C. S. (2011). Cytotoxicity of plasticizers and ionic liquids using drosophila melanogaster $\mathrm{S} 2$ cell culture. Chemical engineering \& technology, 34(3), 429-438.

Ran, D., Cai, S., Wu, H., \&Gu, H. (2012). Di (2-ethylhexyl) phthalate modulates cholinergic mini-presynaptic transmission of projection neurons in Drosophila antennal lobe. Food and chemical toxicology, 50(9), 3291-3297.

Revel, M., Châtel, A., \&Mouneyrac, C. (2018). Micro (nano) plastics: A threat to human health? Current Opinion in Environmental Science \& Health, 1, 17-23.

Roch, S., Friedrich, C., \& Brinker, A. (2020). Uptake routes of microplastics in fishes: practical and theoretical approaches to test existing theories. Scientific Reports, 10(1), 1-12.

Schirinzi, G. F., Pérez-Pomeda, I., Sanchís, J., Rossini, C., Farré, M., \& Barceló, D. (2017). Cytotoxic effects of commonly used nanomaterials and microplastics on cerebral and epithelial human cells. Environmental Research, 159, 579-587.
Smith, M., Love, D. C., Rochman, C. M., \& Neff, R. A. (2018). Microplastics in seafood and the implications for human health. Current environmental health reports, 5(3), 375-386.

Streifel, A. M. (2016). Effect of bisphenol-A on neurodevelopment in Drosophila melanogaster larvae.

Tsai, M. Y., Ho, C. H., Chang, H. Y., Yang, W. C., Lin, C. F., Lin, C. T., ... \& Chang, G. R. (2019). Analysis of Pollution of Phthalates in Pork and Chicken in Taiwan Using Liquid Chromatography-Tandem Mass Spectrometry and Assessment of Health Risk. Molecules, 24(21), 3817 .

Waring, R. H., Harris, R. M., \& Mitchell, S. C. (2018). Plastic contamination of the food chain: A threat to human health? Maturitas, 115, 64-68.

Wright, S. L., \& Kelly, F. J. (2017). Plastic and human health: a micro issue? Environmental science \& technology, 51(12), 6634-6647.

Wright, S. L., Thompson, R. C., \& Galloway, T. S. (2013). The physical impacts of microplastics on marine organisms: a review. Environmental pollution, 178, 483-492.

Yong, C. Q. Y., Valiyaveetill, S., \& Tang, B. L. (2020). Toxicity of microplastics and Nanoplastics in mammalian systems. International Journal of Environmental Research and Public Health, 17(5), 1509.

Zhou, J. J., Zhang, G. A., Huang, W., Birkett, M. A., Field, L. M., Pickett, J. A., \& Pelosi, P. (2004). Revisiting the odorant-binding protein LUSH of Drosophila melanogaster: evidence for odour recognition and discrimination. Febs Letters, 558(1-3), 23-26. 